\title{
ARRASTE VIA FECAL DE NUTRIENTES DA INGESTÃO PRODUZIDO POR BAGAÇO DE MANDIOCA HIDROLISADO
}

\author{
Dorivaldo da Silva Raupp*; Silvia Helena de Paula Marques²; Danielle Amorim Rosa²; Carla \\ Marielle Caldi²; Ana Candida Vivan Cremasco²; David Ariovaldo Banzatto ${ }^{3}$ \\ ${ }^{1}$ Depto. de Zootecnia e Tecnologia de Alimentos - UEPG - Av. Carlos Cavalcanti, 4748 - Campus Uvaranas - Bloco F \\ CEP: 84030-000 - Ponta Grossa, Pr. \\ ${ }_{3}^{2}$ Graduandas do Depto. de Zootecnia e Tecnologia de Alimentos - UEPG. \\ ${ }^{3}$ Depto. de Ciências Exatas - FCAV/UNESP - Campus de Jaboticabal - Rod. Carlos Tonanni, Km 5 - CEP: 14870-000 \\ Jaboticabal, SP. \\ *Autor correspondente <raupp@uepg.br>
}

\begin{abstract}
RESUMO: A ingestão de fibras alimentares pode resultar em arraste de outros nutrientes para as fezes. Bagaço de mandioca produzido por polvilheira foi submetido à hidrólise enzimática para obtenção de um produto mais concentrado em fibra alimentar insolúvel denominado de bagaço de mandioca hidrolisado (BMH). $\mathrm{O} \mathrm{BMH}$ foi avaliado em ensaios biológicos com ratos Wistar quanto a sua habilidade de arrastar os nutrientes da ingestão para as fezes, tendo como padrão de fibra o farelo de trigo (FT). Acréscimo à dieta base, substituindo igual quantidade de amido, de dose de $5 \%, 15 \%$ ou $25 \%$ de $\mathrm{BMH}$ promoveu arraste significativo de minerais (globalidade) ou proteína; dose de $15 \%$ ou $25 \%$ promoveu arraste significativo de lipídeo; e, dose de $25 \%$ promoveu arraste significativo de carboidrato digestível. Dose de $25 \%$ de FT produziu arraste significativo de minerais (globalidade), proteína ou carboidrato digestível, mas, o lipídeo não foi arrastado. $\mathrm{BMH}$ produziu efeito mais pronunciado que FT em arrastar minerais (globalidade) ou proteína para a dose de $5 \%$ ou $15 \%$; no entanto, para a dose alta, de $25 \%$, as fontes produziram efeitos semelhantes em arrastar a proteína, mas o FT promoveu maior arraste de minerais (globalidade). Não houve diferença entre fontes, BMH e FT, em arrastar lipídeo ou carboidrato digestível para as fezes. Na dose alta $(25 \%)$ o BMH promoveu efeitos, no máximo, semelhantes ao FT, em arrastar para as fezes os nutrientes da ingestão; assim, é recomendado como fonte alternativa de fibra alimentar insolúvel para a formulação de alimentos funcionaisdigestivos.
\end{abstract}

Palavras-chave: mandioca, fibra alimentar/dietária, farelo de trigo, nutrição, alimento funcional

\section{NUTRIENT DRAGGING IN FAECES FROM THE INTAKE OF PARTIALLY HYDROLYZED CASSAVA WASTE}

\begin{abstract}
Dietary fiber can drag nutrients in faeces. Cassava waste from starch industry can be hydrolyzed by an enzymatic process and give origin to a food with high content of insoluble dietary fibers, named partially hydrolyzed cassava waste (HCW). $\mathrm{HCW}$ or standard wheat bran (WB) were fed to model growing rats in order to assess their dragging skill of nutrients from the intake of faeces. Addition of $5 \%, 15 \%$ or $25 \% \mathrm{HCW}$, in replacement of starch, promoted a significant dragging proportion for the overall minerals or proteins; addition of $15 \%$ or $25 \% \mathrm{HCW}$ dragged a significant proportion of lipids and the addition of $25 \% \mathrm{HCW}$ dragged a significant proportion of digestible carbohydrates. Adding $25 \%$ WB caused significant dragging of total minerals, protein and digestible carbohydrates, lipids were, however, not dragged with WB treatment. HCW promoted a more pronounced effect as compared to WB in regard to the dragging process of total minerals or proteins for $5 \%$ or $15 \%$ additions. Nervertheless, for high rates, such as $25 \%$ additions, both fibrous sources produced similar effects on the dragging of protein, but WB promoted the greatest dragging process of total minerals. No differences between both fiber sources were observed as to their abilities of dragging lipids or digestible carbohydrates into faeces. With high rates $(25 \%) \mathrm{HCW}$ promoted effects similar to WB, allowing to conclude that $\mathrm{HCW}$ might be used as an important alternative source of insoluble dietary fiber for the formulation of digestive-functional feeds.
\end{abstract}

Key words: cassava, dietary fiber, wheat bran, nutrition, functional food

\section{INTRODUÇÃO}

As unidades de processamento da mandioca para a produção de polvilho azedo e doce, fecularias e polvilheiras, produzem um material sólido identificado por bagaço ou polpa residual, o qual tem sido subaproveitado na forma de farelo para a alimentação de animais. A problemática ambiental decorrente dessa atividade agroindustrial despertou a atenção de pesquisadores da comunidade científica brasileira, os quais passaram a sugerir propostas mais rentáveis de aproveitamento desse descarte, como a produção de xarope de glicose, de etanol (Cereda, 1994; Lorenzoni \& Mella, 1994) e de produto alimentício fibroso para a alimentação humana (Raupp et al., 1999). 
Raupp et al (1999), determinaram a composição nutricional e as propriedades funcionais-digestivas e nutricionais de uma farinha de mandioca fibrosa preparada a partir do bagaço produzido por polvilheira. Os autores encontraram no produto farináceo obtido, em peso seco, $471 \mathrm{~g} \mathrm{~kg}^{-1}$ de amido e $431 \mathrm{~g} \mathrm{~kg}^{-1}$ de fibra alimentar. Proteína, lipídeo e minerais (cinzas) representaram $14 \mathrm{~g} \mathrm{~kg}^{-1}, 4 \mathrm{~g} \mathrm{~kg}^{-1}$ e $10 \mathrm{~g} \mathrm{~kg}^{-1}$ do peso seco da farinha, respectivamente. Essa farinha apresentou, em ratos modelo, propriedade de funcionalidade digestiva característica de produto fibroso, por isso, Raupp et al. (1999) sugeriram o seu aproveitamento para o consumo humano como uma farinha rica em fibra insolúvel, portanto, diferenciada das farinhas de mandioca convencionais.

O incentivo para o consumo de fibras alimentares na dieta humana foi marcante a partir da década de 1970 devido, principalmente, aos benefícios para a saúde atribuídos às fibras. A despeito desse benefício e do crescente incentivo ao consumo de fibras, estudos com animais e humanos, como os citados a seguir, atribuíram a algumas fibras alimentares efeitos adversos específicos, como o de interferir, a nível digestivo, no processo da digestão-absorção de nutrientes conjuntamente ingeridos na dieta (Schweizer \& Edwards, 1992; Johansson et al., 1999).

Michel \& Rerat (1998) avaliaram, em cobaias, a influência de duas fontes de fibra alimentar ( $10 \%$ da dieta), a fibra de beterraba e do farelo de trigo, na absorção de nutrientes para a circulação sangüínea, a partir do intestino delgado e do intestino grosso. As duas fontes de fibra não interferiram na absorção dos nutrientes glicose e aminoácidos (medidos como nitrogênio), no entanto, a quantidade de ácidos graxos voláteis, também medida no sangue portal, foi maior para o grupo que recebeu a fibra de beterraba. Em experimento de maior duração, de 5 para 30 dias, ocorreu diminuição na absorção dos nutrientes a partir do intestino delgado, sem qualquer alteração da absorção, a partir do intestino grosso, dos ácidos graxos voláteis.

Em pessoas saudáveis, foram avaliados o efeito das fibras, inulina e de beterraba, na utilização de nutrientes digestíveis da dieta (Castiglia-Delavaud et al., 1998). Ambas as fontes diminuíram entre 1-2\% a digestibilidade do nitrogênio protéico, do lipídeo e da energia da dieta. Não houve diferença entre grupos, que receberam fibra e o grupo que não recebeu a fibra, para a excreção fecal do nitrogênio ingerido e para o balanço de nitrogênio, no entanto, a excreção urinária de nitrogênio foi claramente menor nos grupos que receberam fibra. Os grupos que receberam fibra apresentaram valores altos para o número de defecações e peso fecal, que os autores atribuíram ao aumento da hidratação da massa fecal e da excreção de massa microbiana. A inulina comercial foi totalmente fermentada e a fibra de beterraba teve um mínimo de fermentação.
Algumas pesquisas citadas por Schweizer \& Edwards (1992) mostraram que a ingestão de fibras, insolúvel ou solúvel, resulta em aumento de nitrogênio fecal, no entanto, outras mostraram que as fibras não interferiram na excreção de proteína para as fezes. A digestibilidade aparente do nitrogênio protéico foi influenciada pela natureza da fibra alimentar, digestibilidade dos carboidratos da dieta, proporção de proteína da dieta, tempo de trânsito e degradabilidade da fibra (Beames \& Eggum, 1981; Eggum et al., 1984; Schweizer \& Edwards, 1992).

Vários estudos apresentaram resultados contraditórios com relação ao efeito das fibras no processo de digestão-absorção dos minerais. Em indivíduos saudáveis, a celulose purificada não interferiu na absorção do zinco e do ferro (Cook et al., 1983), mas, quando fornecida em alta quantidade $\left(16 \mathrm{~g} \mathrm{dia}^{-1}\right)$ para mulheres diminuiu o balanço de cálcio (Slavin \& Marlett, 1980). Em pacientes com ileostomia, a pectina purificada não interferiu na absorção de zinco, cálcio e magnésio, mas reduziu a absorção de ferro (Sandberg et al., 1983); entretanto, quando a pectina, tanto a de baixa como a de alta metoxilação, ou a goma guar ou a ispagula foi incorporada à farinha de trigo para o preparo de pão branco, não houve interferência na absorção de ferro (Cook et al., 1983). Em experimentos de 24 dias de duração e mantendo constante o conteúdo de fitato pela adição de fitato de sódio, pães contendo níveis diferenciados de fibra alimentar (branco, marron e integral), não interferiram na absorção de cálcio, zinco e ferro, sugerindo que a fibra, em si, não influenciou a absorção destes minerais (Andersson et al., 1983).

Agunbiade \& Longe (1998) demonstraram , em ratos, que a casca de um feijão cultivado na África, rica principalmente em potássio e cálcio, causou a diminuição da absorção de minerais, exceto o cálcio. Essa casca era constituída de $354 \mathrm{~g} \mathrm{~kg}^{-1}$ de celulose, $419 \mathrm{~g} \mathrm{~kg}^{-1}$ de hemicelulose + pectina, $36 \mathrm{~g} \mathrm{~kg}^{-1}$ de lignina, bem como quantidades de $114 \mathrm{~g} \mathrm{~kg}^{-1}$ de proteína bruta, $26 \mathrm{~g} \mathrm{~kg}^{-1}$ de lipídeo, 0,82 $\mathrm{g} \mathrm{kg}^{-1}$ de ácido fítico e $0,23 \mathrm{~g} \mathrm{~kg}^{-1} \mathrm{de}$ fósforo-fitina.

Em pesquisa conduzida em ratos modelo, por Raupp \& Sgarbieri (1996), foi demonstrado que, em dose de $3 \%$ ou $9 \%$ da dieta, a fibra solúvel extraída do feijão Phaseolus vulgaris promoveu menor absorção aparente de minerais do que a fibra insolúvel; no entanto, não houve diferença significativa entre as fibras com relação a absorção aparente de proteína. O acréscimo de qualquer das fibras, insolúvel ou solúvel, de $3 \%$ para $9 \%$ da dieta, diminuiu a absorção aparente de minerais e de proteína. Uma fibra solúvel de alta viscosidade extraída também desse feijão, mas que, não foi hidrolisada previamente pelas enzimas do suco pancreático, promoveu, em contraste, maior absorção aparente de minerais para a dose de $9 \%$ e menor absorção de proteína, em comparação com a celulose purificada. $\mathrm{O}$ acréscimo da fibra solúvel de alta viscosidade de $3 \%$ 
para $9 \%$ da dieta, também diminuiu a absorção aparente de proteína, porém, não afetou a absorção aparente de minerais.

Schweizer \& Edwards (1992) relacionaram as propriedades de ionização e degradabilidade de fibras solúveis, como as pectinas, alginatos, carragenas, com a biodisponibilidade de minerais ingeridos na dieta. No estômago, devido ao baixo $\mathrm{pH}$, estas fibras podem estar não-ionizáveis, mas, no $\mathrm{pH}$ mais alto do intestino delgado readquirem suas cargas e podem ligar eletrostaticamente os minerais, arrastando-os até o intestino grosso. No cólon, as fibras solúveis fermentescíveis são degradadas, por isso, diminuem a capacidade de ligar os minerais e contribuem para o $\mathrm{pH}$ baixo da matéria fecal (Reddy et al., 1998). O pH baixo do conteúdo intra-colônico também diminui a capacidade dessas fibras solúveis, como de outras substâncias que apresentem grupos urônicos ou acídicos, de ligarem minerais. Assim, ambos os fatores de ocorrência no cólon abrandam o arraste de minerais ingeridos para as fezes.

Diversos autores (Kelsay et al., 1978; Schwartz \& Levine, 1980; Vahouny et al., 1980; Wu et al., 1980; Falk \& Nagyvary, 1982; Sandberg et al., 1983; Blackburn et al., 1984; Gallaher \& Schneeman, 1985; Johnson \& Gee, 1986; Meyer et al., 1986; Rainbird \& Low, 1986; Ebihara \& Schneeman, 1989; Davies et al., 1991; Schweizer \& Edwards, 1992; Raupp \& Sgarbieri, 1996) relacionaram também a viscosidade do conteúdo do intestino delgado com o aproveitamento, pelo organismo, de nutrientes ingeridos. Segundo eles, vários fatores contribuem para explicar a ação das fibras viscosas em retardar a absorção de nutrientes para a circulação sangüínea, entre eles a ação anti-motilidade, que torna mais lento o movimento peristáltico propulsivo e de mistura (revolvimento), parece ser o mecanismo dominante.

Alam et al. (1998) mostraram que a goma guar parcialmente hidrolisada, portanto menos viscosa, aparentemente não interferiu com a absorção normal de glicose, aminoácido e lipídeo. Em concordância com esses dados, não houve alteração da função pancreática exócrina.O Psyllium, por permanecer mais tempo no intestino, prolonga a saciedade e produz achatamento e alongamento das curvas pós-prandiais para a glicose, a insulina e os triglicerídeos no soro (Rigaud et al., 1998).

A pesquisa em foco teve como proposta avaliar, em ratos modelo e a nível de trato digestivo, os efeitos de um produto alimentício de alta concentração em fibra alimentar insolúvel, o "bagaço de mandioca hidrolisado", no balanço digestivo dos nutrientes minerais (globalidade), proteína, lipídeo e carboidrato digestível, tendo como padrão de fibra alimentar o farelo de trigo.

\section{MATERIAL E MÉTODOS}

O produto alimentício de alta concentração em fibra alimentar insolúvel denominado "bagaço de mandioca hidrolisado (BMH)" foi preparado no Laboratório de Tecnologia de Alimentos - UEPG e a partir do bagaço de mandioca produzido como descarte sólido pela Polvilheira Santa Rosa, localizada no município de Tibagi, Paraná. Para o processo de hidrólise enzimática aplicado na matéria-prima bagaço de mandioca da polvilheira foram utilizadas enzimas comerciais fornecidas pela Novo Nordisk Bioindustrial do Brasil Ltda, a thermamyl e a amiloglucosidase (AMG) para a sacarificação do amido remanescente, mais a enzima pectinex, de ação nas fibras constituintes da parede celular, para melhorar a eficiência do processo de hidrólise. As especificações para obter ação máxima das enzimas estão apresentadas na Tabela 1 e foram dadas pelo fornecedor.

A matéria sólida que resistiu ao processo de hidrólise aplicado (Figura 1), depois de separada da porção líquida por filtração e seguida de lavagem com água corrente, foi secada em estufa com circulação de ar na temperatura regulada entre 60 a $70^{\circ} \mathrm{C}$ e homogeneizada em liqüidificador industrial para resultar no produto de alta concentração em fibra alimentar, especificado como "Bagaço de Mandioca Hidrolisado (BMH)". A composição centesimal do produto BMH ou do padrão farelo de trigo (FT) foi determinada segundo os métodos publicados na AOAC (1984) para a umidade, minerais (como cinzas), proteína, lipídeo. A fibra alimentar/dietária foi determinada pelo método de Prosky et al. (1988) com modificações para adaptação à condições de trabalho do laboratório, e a fração carboidrato digestível foi determinada por diferença porcentual.

$\mathrm{O} \mathrm{BMH}$ foi incorporado à dietas as quais foram fornecidas para ratos modelo em fase de crescimento e durante os ensaios biológicos, tendo por fim avaliar os efeitos de seus constituintes fibrosos no balanço digestivo dos nutrientes minerais (globalidade), proteína, lipídeo e carboidrato digestível. O FT (farelo de trigo) foi usado como padrão de fonte de fibra.

O ensaio consistiu de sete tratamentos de seis ratos/tratamento, alojados individualmente segundo o delineamento em blocos ao acaso. Três tratamentos receberam o $\mathrm{BMH}$ nas doses de $5 \%, 15 \%$ ou $25 \%$; três tratamentos receberam FT como padrão de comparação também nas doses de $5 \%, 15 \%$ ou $25 \%$; e, um tratamento não recebeu fonte de fibra. Para o preparo

Tabela 1 - Especificações para obtenção da ação máxima das enzimas.

\begin{tabular}{lccc}
\hline Enzimas & $\begin{array}{c}\text { Recomendações } \\
\text { do fabricante }\end{array}$ & $\mathrm{pH}$ & $\begin{array}{c}\text { Temperatura / Tempo } \\
\text { de reação }\end{array}$ \\
\hline Thermamyl & $0,5 \mathrm{~kg} \mathrm{t}^{-1}$ amido & 5,6 & $90-95^{\circ} \mathrm{C} / 3 \mathrm{~h}$ \\
AMG & $1,13 \mathrm{~kg} \mathrm{t}^{-1}$ amido & 4,5 & $60^{\circ} \mathrm{C} / 15 \mathrm{~h}$ \\
Pectinex & $\begin{array}{c}20 \mathrm{~kg} \mathrm{t}^{-1} \mathrm{MS} \text { do } \\
\text { substrato }\end{array}$ & 5,6 & $50^{\circ} \mathrm{C} / 3 \mathrm{~h}$ \\
\hline
\end{tabular}


das dietas foram utilizados ingredientes de diversas procedências: caseína contendo $90,39 \%(\% \mathrm{~N} \times 6,40)$ de proteína, em base seca; óleo refinado de soja; amido de milho fornecido pelo produto comercial "maizena" de grau de pureza igual a 99,8\%, em base seca; mistura de vitaminas e mistura de sais minerais, preparadas em laboratório segundo a formulação da AIN-93G (Reeves et al., 1993). A dieta básica foi preparada segundo a formulação da AIN-93G (Reeves et al., 1993) para conter: caseína $20 \%$; óleo de soja $7 \%$; mistura mineral $3,5 \%$; mistura vitamínica $1 \%$; L-cistina $0,3 \%$; bitartarato de colina $0,25 \%$. O amido, única fonte de carboidrato digestível da dieta base, foi utilizado em q.s.p. $100 \%$. 0 BMH ou o padrão FT entraram como única fonte de fibra alimentar na formulação das dietas para os ratos modelo e nas doses de $5 \%, 15 \%$ ou $25 \%$, em substituição a igual porcentagem de amido. A formulação da AIN-93G (Reeves et al., 1993) fornece $5 \%$ de fibra para uma dieta normal.

Os animais modelo utilizados foram ratos albinos da linhagem Wistar, SPF (Livres de Patógenos Específicos), de 21 dias e fornecidos pelo Biotério Central da Universidade Federal de Santa Catarina (UFSC). Durante o ensaio, realizado no Laboratório de Ensaios Biológicos da UFSC, a temperatura do laboratório foi mantida a $21 \pm 2^{\circ} \mathrm{C}$, com alternância automática de claro-escuro em períodos de 12 horas. Os animais receberam dieta e água ad libitum. $O$ ensaio teve duração de 33 dias, incluindo 5 dias de adaptação ao ambiente de experimentação e 28 dias para coleta de dados.

Durante o ensaio foram coletadas, para cada rato, as fezes e determinado o seu peso seco, bem como, determinado o peso de alimento ingerido. A matéria fecal e uma amostragem da dieta de cada

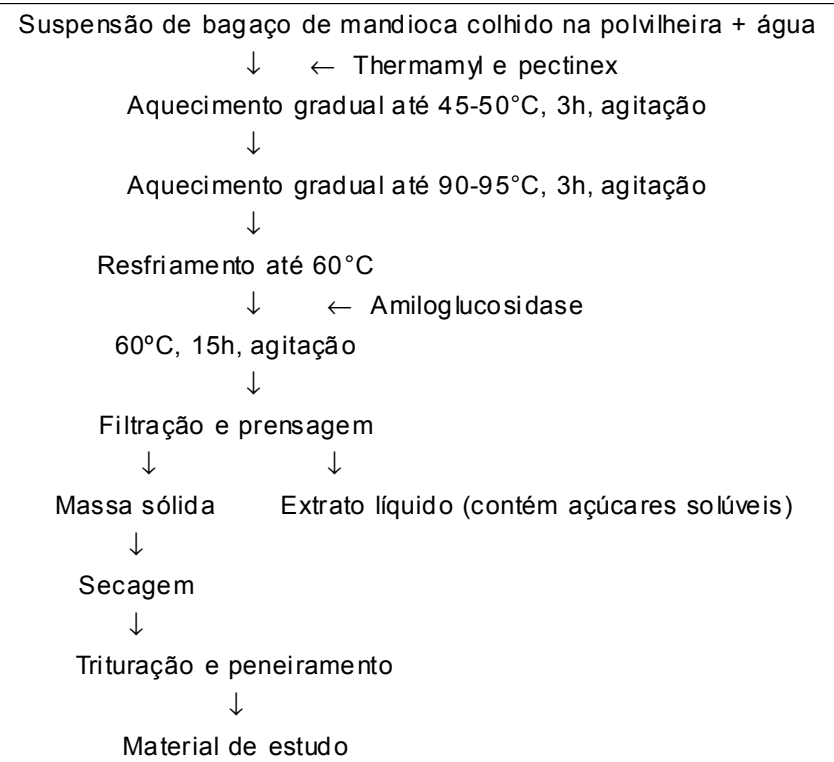

Figura 1 - Fluxograma da hidrólise do bagaço de mandioca produzido pela polvilheira. tratamento foram guardadas em freezer até o momento de uso. Nesse material foi determinada a umidade, os minerais (como cinzas), a proteína e o lipídeo segundo os métodos publicados na AOAC (1984). A fibra alimentar/dietária foi determinada pelo método de Prosky et al. (1988) com modificações para adaptação à condição de trabalho do laboratório. A fração carboidrato digestível foi determinada por diferença porcentual. $O$ balanço digestivo do nutriente foi calculado, para cada rato, a partir das informações analíticas do nutriente determinadas na dieta e nas fezes produzidas pelo rato, do peso ingerido do nutriente e do peso excretado nas fezes do nutriente.

Os dados foram analisados através da análise de variância e as médias de tratamentos foram comparadas pelo teste de Tukey $(P<0,05)$, segundo Banzatto \& Kronka (1995).

\section{RESULTADOS E DISCUSSÃO}

O produto farináceo "bagaço de mandioca hidrolisado (BMH)" apresentou 1,6 vezes mais fibra alimentar que o padrão farelo de trigo (FT) $(60,9 \%$ contra $37,7 \%)$, proporção semelhante de carboidrato digestível (24,6\% contra $24,7 \%)$, porém, apresentou cerca de uma quarta parte de proteína $(4,7 \%$ contra $17,5 \%)$ e de lipídeo $(0,7 \%$ contra $3,0 \%)$ e cerca de $40 \%$ das cinzas $(2,2 \%$ contra 5,6\%) (Tabela 2).

Os resultados dos ensaios biológicos realizados em ratos modelo, através dos quais foram avaliados os efeitos do BMH e do FT no arraste para as fezes dos nutrientes, minerais (globalidade), proteína, lipídeo e carboidrato (ch.) digestível, estão apresentados, na Tabela 3. O acréscimo de doses de $5 \%, 15 \%$ ou $25 \%$ da fonte de fibra BMH ou da FT à dieta base (tratamento sem a fonte de fibra $=$ Sem FF) produziram efeitos diferenciados $(P<0,05)$ em arrastar para as fezes dos ratos ensaiados os nutrientes, minerais (globalidade), proteína, lipídeo e ch. digestível, os quais foram ingeridos conjuntamente na dieta.

Nos tratamentos contendo o $\mathrm{BMH}$, em doses de $5 \%, 15 \%$ ou $25 \%$ da dieta, os minerais (globalidade) ingeridos na dieta foram arrastados para as fezes em proporções expressivas, respectivamente, igual a $33,9 \%, 56,8 \%$ ou $66,1 \%$, e estas foram crescentes $(P<0,05)$ em função do acréscimo à dieta da fonte $\mathrm{BMH}$, bem como maiores que o valor de $15,3 \%$ determinado para o tratamento sem FF (Tabela 3). Entre os ratos em dieta contendo a fonte $\mathrm{FT}$, aqueles do tratamento que recebeu dieta contendo o maior acréscimo dessa fonte, igual a $25 \%$, foram os únicos que produziram o arraste $(P<0,05)$ de minerais (globalidade) ingeridos para as fezes $(77,8 \%$ da ingestão foi excretada nas fezes), em comparação com os ratos que receberam a dieta sem $\mathrm{FF}$ e os que receberam a dieta contendo dose de $5 \%$ ou $15 \%$ da fonte FT (Tabela 3). 
Tabela 2 - Composição (base seca) ${ }^{1}$ das fontes de fibra alimentar utilizadas na formulação de dietas para alimentar ratos modelo.

\begin{tabular}{|c|c|c|c|c|c|}
\hline Fonte de fibra & Fibra alimentar & Carboidrato digestível ${ }^{4}$ & Prote ína & Lipídio & Cinzas \\
\hline & & \% & & & \\
\hline $\begin{array}{l}\text { Bagaço de mandioca } \\
\text { hidrolisado }(\mathrm{BMH})^{2}\end{array}$ & 60,9 & 24,6 & 4,7 & 0,7 & 2,2 \\
\hline Farelo de trigo $(\mathrm{FT})^{3}$ & 37,7 & 24,7 & 17,5 & 3,0 & 5,6 \\
\hline
\end{tabular}

${ }^{1}$ média de três determinações analíticas; ${ }^{2}$ matéria sólida que sobrou depois da hidrólise, utilizando as enzimas amilolíticas, thermamyl e amiloglucosidase, e as de ação na parede celular, pectinex, seguida de lavagem com água, secagem e triturada em liqüidificador industrial; ${ }^{3}$ obtido do comércio; ${ }^{4}$ estimado por diferença porcentual.

Tabela 3 - Proporção de nutriente ingerido que foi excretada na matéria fecal produzida pelo rato, conjuntamente com a fibra alimentar, durante 28 dias de ensaio biológico.

\begin{tabular}{|c|c|c|c|c|c|c|c|}
\hline \multirow{3}{*}{ Variável } & \multicolumn{7}{|c|}{ Tratamento } \\
\hline & \multirow{2}{*}{$\begin{array}{c}0 \% \\
\text { Sem FF }\end{array}$} & \multicolumn{2}{|c|}{$5 \%$} & \multicolumn{2}{|c|}{$15 \%$} & \multicolumn{2}{|c|}{$25 \%$} \\
\hline & & $\mathrm{BMH}$ & $\mathrm{FT}$ & $\mathrm{BMH}$ & $\mathrm{FT}$ & $\mathrm{BMH}$ & $\mathrm{FT}$ \\
\hline Mineral & $15,3 \mathrm{e}$ & $33,9 d$ & $14,6 \mathrm{e}$ & $56,8 \mathrm{c}$ & $18,0 \mathrm{e}$ & $66,1 \mathrm{~b}$ & $77,8 \mathrm{a}$ \\
\hline Prote ína & $5,2 \mathrm{~d}$ & $12,1 \mathrm{c}$ & $5,0 \mathrm{~d}$ & $17,4 \mathrm{~b}$ & $5,8 d$ & $20,7 a$ & $20,4 a$ \\
\hline Lipídeo & $0,7 \mathrm{c}$ & $2,1 \mathrm{bc}$ & $0,7 \mathrm{c}$ & $5,2 a b$ & $1,8 \mathrm{bc}$ & $6,0 \mathrm{a}$ & $3,5 \mathrm{abc}$ \\
\hline Ch. digestível & $0,2 \mathrm{c}$ & $0,7 \mathrm{bc}$ & $0,2 \mathrm{c}$ & $1,3 \mathrm{bc}$ & $0,5 \mathrm{c}$ & $2,7 \mathrm{a}$ & $1,6 a b$ \\
\hline
\end{tabular}

Valores na horizontal com letras distintas diferem $(P<0,05)$; Sem $\mathrm{FF}=$ sem fonte de fibra; $\mathrm{BMH}=$ bagaço de mandioca hidrolisado, matéria sólida que sobra depois da hidrólise utilizando as enzimas amilolíticas, thermamyl e amiloglucosidase, e as de ação na parede celular, pectinex, seguida de lavagem com água, desidratada e triturada em liqüidificador industrial; FT=farelo de trigo obtido do comércio.

Também foi feita avaliação comparativa entre os tratamentos que receberam a fonte $\mathrm{BMH}$ e a $\mathrm{FT}$ para cada dose da fonte fibrosa incorporada à dieta dos ratos ensaiados, igual a $5 \%, 15 \%$ ou $25 \%$. Para a dose de $5 \%$ ou $15 \%$, os ratos que receberam dieta contendo a fonte $\mathrm{BMH}$ produziram o maior $(P<0,05)$ arraste de minerais para as fezes, valores de $33,9 \%$ para o $\mathrm{BMH}$ contra $14,6 \%$ para o $\mathrm{FT}$ ou valores de $56,8 \%$ para o $\mathrm{BMH}$ contra $18,0 \%$ para o $\mathrm{FT}$, respectivamente (Tabela 3 ). No entanto, para a maior dose testada $(25 \%)$, os ratos que receberam a fonte FT produziram o maior $(P<0,05)$ arraste de minerais ingeridos conjuntamente na dieta para as fezes, $77,8 \%$ para o FT contra $66,1 \%$ para o BMH (Tabela 3).

Estes resultados, aparentemente, contrastam com os de alguns pesquisadores citados por Schweizer \& Edwards (1992), de que, a fibra alimentar não promove, qualquer efeito nutricionalmente significativo na absorção de minerais. Para aqueles autores, outras substâncias de natureza química não fibrosa mas que permanecem associadas com as fibras alimentares é que estariam relacionadas com as perdas para as fezes dos nutrientes da ingestão.

Para Toma \& Curtis (1986), os cátions Zn, Fe, $\mathrm{Mg}$ e Ca foram afetados na absorção pelas fibras alimentares. Segundo eles, a associação com ácidos fíticos e compostos polifenólicos também contribuíram para a deficiência da absorção desses minerais. Lönnerdal et al.(1984) demonstraram o efeito negativo de fitatos e alguns de seus produtos de degradação sobre o zinco e o ferro. Com relação ao ferro, tem sido demonstrado efeito negativo na absorção até para os níveis baixos de fitatos na dieta. $\mathrm{E}$, em experimentos com farelos de cereais e administrados para humanos foi demonstrado o efeito do fitato em reduzir a absorção de ferro e zinco. Alguns dos compostos fenólicos constituintes de alimentos vegetais também prejudicaram a absorção de ferro. Mas, apesar dos resultados experimentais, o papel do fitato foi questionado por Simpson et al., citado por Schweizer \& Edwards (1992), em estudo extensivo com humanos.

Com relação à proteína também ocorreu aumento $(P<0,05)$ de seu arraste para as fezes quando os ratos receberam a fonte $\mathrm{BMH}$ nas doses crescentes de $5 \%, 15 \%$ ou $25 \%$, em proporção igual a, respectivamente, $12,1 \%, 17,4 \%$ ou $20,7 \%$ do total ingerido, valores estes também maiores $(P<0,05)$ que os $5,2 \%$ determinados para o arraste da proteína ingerida pelos ratos do tratamento sem FF. Entre os tratamentos com a fonte $\mathrm{FT}$, à semelhança do que ocorreu com os minerais, somente os ratos que receberam dieta contendo o maior acréscimo dessa fonte, igual a $25 \%$, produziram aumento $(P<0,05)$ da proteína ingerida para as fezes, em proporção de $20,4 \%$, sendo que não houve diferença $(P<0,05)$ entre os dois outros tratamentos e o tratamento sem FF (Tabela 3).

$\mathrm{O}$ efeito comparativo das fontes de fibra $\mathrm{BMH}$ e FT no arraste para as fezes do nutriente proteína ingerida também foi avaliado e os dados estão apresentados na Tabela 3. Para a dose de $5 \%$ ou $15 \%$ acrescentada à dieta, à semelhança do efeito sobre os minerais (globalidade), os ratos que receberam dieta contendo a fonte $\mathrm{BMH}$ produziram o maior $(P<0,05)$ arraste de proteína para as fezes, $12,1 \%$ para o $\mathrm{BMH}$ contra $5,8 \%$ para o FT ou $17,4 \%$ para o BMH contra $5,8 \%$ para o $\mathrm{FT}$, respectivamente. No entanto, para a dose de $25 \%$ as fontes não diferiram $(P<0,05)$ entre si, $20,7 \%$ para o $\mathrm{BMH}$ contra $20,4 \%$ para o $\mathrm{FT}$. 
A absorção de nitrogênio parece ser afetada quando é ingerida dieta contendo alta proporção de fibra alimentar, e as proteínas associadas à fibra dos alimentos naturais parecem ser menos digestíveis devido a sua íntima associação com a matriz da parede celular vegetal (Toma \& Curtis, 1986).

As fibras alimentares, solúvel e insolúvel, atuam de modo diferenciado sobre a digestibilidade e utilização das proteínas. A fibra insolúvel, como a dos cereais, é minimamente degradada pelas bactérias fermentescíveis intestinais e, por isso, aumenta a excreção de nitrogênio fecal, em parte, por indisponibilizar a proteína da própria fonte fibrosa, ou, por complexar-se com proteína que foi fornecida através da dieta e tornando-a não-digestível ou não-degradada pela flora microbiana intestinal. Já a fibra solúvel, como a encontrada em frutas e hortaliças, é totalmente fermentescível, e, por isso, contribui para a excreção relativamente alta da proteína de origem microbiana. $\mathrm{O}$ efeito total de ambas as fibras, solúvel e insolúvel, é a diminuição da digestibilidade aparente da proteína (Schweizer \& Edwards, 1992).

$\mathrm{O}$ efeito da fonte BMH ou FT em arrastar lipídeos e carboidratos digestíveis da ingestão para as fezes foi, em contraste com os minerais e as proteínas, pouco pronunciado. Nos ratos dos tratamentos que receberam as doses mais altas, iguais a $15 \%$ ou $25 \%$ de $\mathrm{BMH}$, o nutriente lipídeo da dieta foi arrastado para as fezes em proporções respectivamente de $5,2 \%$ e $6,0 \%$, as quais foram maiores $(P<0,05)$ do que a encontrada para 0 tratamento sem $\mathrm{FF}$, que foi de $0,7 \%$ de excreção. $\mathrm{O}$ tratamento de $25 \%$ diferiu $(P<0,05)$ daquele que recebeu o menor acréscimo de $\mathrm{BMH}$, igual a $5 \%$. Doses da fonte FT, também iguais a $5 \%, 15 \%$ ou $25 \%$, em contraste, não arrastaram para as fezes o lipídeo ingerido pelos ratos conjuntamente na dieta, em comparação com o tratamento sem FF (Tabela 3).

O efeito da fonte de fibra BMH sobre a proporção excretada do lipídeo ingerido conjuntamente na dieta não diferiu $(P<0,05)$ do efeito produzido pela fonte $\mathrm{FT}$. Para os tratamentos com a dose de $5 \%$ a proporção de arraste foi de $2,1 \%$ para o $\mathrm{BMH}$ contra $0,7 \%$ para o $\mathrm{FT}$, para os tratamentos com a dose de $15 \%$ a proporção foi de $5,2 \%$ para o $\mathrm{BMH}$ contra $1,8 \%$ para o $\mathrm{FT}$, e, para a dose de $25 \%$ a proporção foi de $6,0 \%$ para o $\mathrm{BMH}$ contra $3,5 \%$ para o FT (Tabela 3).

O efeito da fonte de fibra BMH ou FT no arraste do nutriente $\mathrm{ch}$. digestível ingerido conjuntamente na dieta também foi avaliado e os dados estão apresentados na Tabela 3. Entre os tratamentos que receberam a fonte $\mathrm{BMH}$, somente o tratamento contendo a alta dose dessa fonte, igual a $25 \%$, produziu, em contraste com o tratamento contendo dose de $5 \%$ ou $15 \%$, maior arraste do ch. digestível ingerido para as fezes e na proporção de $2,7 \%$, a qual foi maior $(P<0,05)$ do que a de todos os demais tratamentos. Não foi observada diferença $(P<0,05)$ entre três tratamentos, o que recebeu a dose de $5 \%$ de $\mathrm{BMH}$, o que recebeu a dose de $15 \%$ de $\mathrm{BMH}$ e aquele sem FF.

Dentre os tratamentos que receberam a fonte $\mathrm{FT}$, somente a maior dose, igual a $25 \%$, produziu efeito marcante nos ratos, sendo o arraste de ch. digestível para as fezes igual a $1,6 \%$ da ingestão, valor maior $(P<0,05)$ em comparação com os $0,2 \%, 0,2 \%$ e $0,5 \%$ determinados, respectivamente, para o tratamento sem FF, o tratamento contendo a dose de $5 \%$ de FT e o tratamento contendo a dose de $15 \%$ de FT (Tabela 3 ).

A comparação entre as duas fontes de fibra no arraste do nutriente ch. digestível da ingestão para as fezes mostra que, o efeito do BMH não diferiu $(P<0,05)$ do efeito produzido pela fonte $\mathrm{FT}$, para qualquer das doses testadas, $5 \%, 15 \%$ ou $25 \%$. Para os tratamentos com a dose de $5 \%$ a proporção foi de $0,7 \%$ para o $\mathrm{BMH}$ contra $0,2 \%$ para o $\mathrm{FT}$, para os tratamentos com a dose de $15 \%$ a proporção foi $1,3 \%$ para o $\mathrm{BMH}$ contra $0,5 \%$ para o FT e para os tratamentos com a dose de $25 \%$ a proporção foi igual a 2,7\% para o BMH contra $1,6 \%$ para o FT (Tabela 3).

Com base nos dados da Tabela 3 e na discussão apresentados, ficou claro que o BMH promoveu o arraste para a matéria fecal dos nutrientes minerais (globalidade) e proteína ingeridos conjuntamente na dieta já quando essa fonte fibrosa foi acrescentada à dieta na dose baixa igual a $5 \%$, enquanto que, o arraste de lipídeo foi marcante somente para o acréscimo de $15 \%$ ou $25 \%$ dessa fonte e o arraste de ch. digestível somente foi marcante para o acréscimo de $25 \%$ da fonte $\mathrm{BMH}$ à dieta. O padrão FT promoveu o arraste de minerais, de proteína e de ch. digestível, todos ingeridos conjuntamente, somente quando foi acrescentado à dieta uma dose alta, igual a $25 \%$, dessa fonte fibrosa. Qualquer dose testada da fonte FT, igual a $5 \%, 15 \%$ ou $25 \%$, não produziu efeito de arraste para as fezes sobre o lipídeo ingerido. O BMH produziu efeito mais pronunciado do que a fonte FT em arrastar os minerais (globalidade) para as fezes tanto para a dose baixa da dieta igual a $5 \%$ como para a dose média igual a $15 \%$, no entanto, para a dose alta da dieta igual a $25 \%$ a FT promoveu um maior arraste de minerais para a matéria fecal. O BMH arrastou maiores proporções de proteína ingerida para as fezes do que a fonte $\mathrm{FT}$, também para as doses de $5 \%$ ou $15 \%$, porém, na dose mais alta de $25 \%$ ambas as fontes produziram efeito semelhante. Com relação ao efeito sobre o arraste de lipídeo e de ch. digestível para as fezes dos ratos, não houve diferença entre as fontes.

Os efeitos das fibras alimentares no aproveitamento dos nutrientes da dieta pelo organismo parece serem dependentes da composição química, estrutura e outras características físicas do produto fibroso, como a viscosidade e a granulometria das partículas. A ingestão de fibra solúvel viscosa e purificada, como gomas e pectinas, retarda e diminui a absorção de nutrientes, enquanto que fontes insolúveis, 
como o farelo de trigo, produzem pouco efeito na absorção de nutriente no intestino delgado. E, substâncias indigestíveis da dieta devido a porosidade adsorvem nutrientes de baixo peso molecular e, assim, a granulometria delas pode estar relacionada com a absorção de nutrientes para a circulação sangüínea. Partículas maiores, por possuírem menor grau de porosidade e por conseguinte menor área superficial, liberam menos nutrientes de baixo peso molecular para absorção no epitélio intestinal, portanto, retardam a velocidade de sua absorção para a circulação sangüínea (Schweizer \& Edwards, 1992).

A diferença entre as fontes BMH e FT para o efeito de arraste dos nutrientes ingeridos até as fezes não deve ser atribuída à granulometria destes produtos, pois os resultados desta para ambas as fontes foram muito próximos. Mas, a composição química da fibra alimentar pode explicar, fundamentalmente, os resultados obtidos na pesquisa em foco. $\mathrm{O} B M H$ foi constituído de fibra alimentar insolúvel e apresentou 1,6 vezes mais fibra que o padrão $\mathrm{FT}(60,9 \%$ contra $37,7 \%$ ); também, as fontes $\mathrm{BMH}$ ou $\mathrm{FT}$ foram aproveitadas de forma diferenciada pelo organismo dos ratos modelo, principalmente com relação ao nutriente fibra alimentar.

Os resultados da pesquisa confirmam as pesquisas prévias, de que fibras alimentares constituintes da dieta promovem o arraste de nutrientes ingeridos para as fezes, como os minerais, as proteínas, os lipídeos e os carboidratos digestíveis, portanto, restringem o seu aproveitamento para o organismo. O arraste é influenciado pelos constituintes da fibra bem como pela proporção da fibra na dieta.

\section{AGRADECIMENTOS}

Ao CNPq/PIBIC-UEPG por conceder uma bolsa de iniciação científica, ago/99-jul/00; à Polvilheira Santa Rosa, Tibagi-PR por fornecer a matéria-prima bagaço de mandioca; à Novo Nordisk Bioindustrial do Brasil Ltda, Araucária-PR, pela doação das enzimas; à Universidade Federal de Santa Catarina por fornecer os ratos e permitir a realização dos ensaios biológicos; aos técnicos do Laboratório de Tecnologia de Alimentos-UEPG, pelo apoio; e ao professor Dr. André Belmont Pereira do curso de Agronomia-UEPG por revisar o abstract.

\section{REFERÊNCIAS BIBLIOGRÁFICAS}

AGUNBIADE, S.O.; LONGE, O.G. African yam bean hull chemical composition and its effects on rat's mineral retention, serum biochemical components and enzymatic activities. Nahrung, v.42, p.89-93, 1998

ALAM, N.H.; MEIER, R.; RAUSCH, T.; MEYER-WYSS, B.; HILDEBRAND, P.; SCHNEIDER, H.; BACHMANN, C.; MINDER, E.; FOWLER, B.; GYR, $K$. Effects of a partially hidrolized guar gum on intestinal absorption of carbohydrate, protein and fat: a double-blind controlled study in volunteers. Clinical Nutrition, v.17, p.125-129, 1998.

ANDERSSON, H.; NÄVERT, B.; BINGHAM, S.R.; ENGLYST, H.N.; CUMMINGS, J.H. The effects of breads containing similar amounts of phytate but different amounts of wheat bran on calcium, zinc and iron balance in man. British Journal of Nutrition, v.50, p.503-510, 1983.
ASSOCIATION OF OFFICIAL ANALYTICAL CHEMISTS. Official methods of analysis. 14.ed. Washington: AOAC, 1984.

BANZATTO, D.A.; KRONKA, S.N. Experimentação agrícola. 3.ed. Jaboticabal: FUNEP; UNESP, FCAV, 1995. 247p.

BEAMES, R.M.; EGGUM, B.O. The effect of type and level of protein, fibre and starch on nitrogen excretion patterns in rats. British Journal of Nutrition, v.46, p.301-313, 1981.

BLACKBURN, N.A.; HOLGATE, A.M.; READ, N.W. Does guar gum improve postprandial hyperglycaemia in humans by reducing small intestinal contact area? British Journal of Nutrition, v.52, p.197-204, 1984

CASTIGLIA-DELAVAUD, C.; VERDIER, E.; BESLE, J.M.; VERNET, J. BOIRIE, Y.; BEAUFRERE, B.; De BAYNAST, R.; VERMOREL, M. Net energy value of no-starch polysaccharide isolates (sugarbeet fibre and commercial inulin) and their impact on nutrient digestive utilization in healthy human subjects. British Journal of Nutrition, v.80, p.343-352, 1998.

CEREDA, M.P. Caracterização dos resíduos da industrialização da mandioca. In: CEREDA, M.P. (Cood.) Resíduos da industrialização da mandioca no Brasil. São Paulo: Paulicéia, 1994. p.11-50.

COOK, J.D.; NOBLE, N.L.; MORCK, T.A.; LYNCH, L.R ; PETERSBURG, S.J. Effect of fibre on nonheme iron absorption. Journal of Gastroenterology, v.85, p.1354-1358, 1983.

DAVIES, J.R.; BROWN J.C.; LIVESEY, G. Energy values and energy balance in rats fed on suplements of guar gum or cellulose. British Journal of Nutrition, v.65, p.415-433, 1991.

EBIHARA, K: SCHNEEMAN, B.O. Interaction of bile acids, phospholipids, cholesterol and triglyceride with dietary fibres in the small intestine of rats. Journal of Nutrition, v.119, p.1100-1106, 1989.

EGGUM, B.O.; BEAMES, R.M.; WOLSTRUP, J.; BUCH KNUDSEN, K.E. The effect of protein quality and fibre level in the diet and microbial activity in the digestive tract on protein utilization and energy digestibility in rats. British Journal of Nutrition, v.51, p.305-314, 1984.

FALK, J.D.; NAGYVARY, J.J. Exploratory studies of lipid-pectin interactions. Journal of Nutrition, v.112, p.182-188, 1982.

GALLAHER, G.; SCHNEEMAN, B.O. Effect of dietary cellulose on site of lipid absorption. American Journal of Physiology, v.249, p.G184-G191, 1985.

JOHANSSON, L.; THELLE, D.S.; SOLVOLL, K.; BJORNEBOE, G.E.; DREVON, C.A. Healthy dietary habits in relation to social determinants and lifestyle factors. British Journal of Nutrition, v.81, p.211-220, 1999

JOHNSON, I.T.; GEE, J.M. Gastrointestinal adaptation in response to soluble non-available polysaccharides in the rat. British Journal of Nutrition, v.55, p.497-505, 1986

KELSAY, J.L.; BEHALL, K.M.; PRATHER, E.S. Effect of fibre from fruits and vegetables on metabolic responses of human subjects. I. Bowel transit times, number of defecations, fecal weight, urinary excretion of energy and nitrogen and apparent digestibilities of energy, nitrogen and fat. American Journal of Clinical Nutrition, v.31, p.1135-1149, 1978.

LÖNNERDAL, B.; CEDERBLAD, A.; DAVIDSSON, L.; SANDSTRÖM, B. The effect of individual components of soy formula and cow's milk formula on zinc bioavailability. American Journal of Clinical Nutrition, v.40, p.10641070, 1984.

LORENZONI, W.R.; MELLA, S.C. Avaliação do resíduo sólido obtido da lavagem da raiz da mandioca como alimento energético para bovinos. In: CEREDA, M.P. (Cood.) Resíduos da industrialização da mandioca no Brasil. São Paulo: Paulicéia, 1994. p.91-99.

MEYER, J.H.; ELASHOFT, Y.G.J.; REEDY, T.; FRESSMAN, J.; AMIDON, G. Effects of viscosity and fluid outflow on postcibal gastric emptying of solids. American Journal of Physiology, v.250, p.G161-G164, 1986.

MICHEL, P.; RERAT, A. Effect of adding sugar beet fibre and wheat bran to a starch diet on the absorption kinetics of glucose, amino-nitrogen and volatile fatty acids in the pig. Reproduction, Nutrition, Development, v.38, p.49-68, 1998

PROSKY, L.; ASP, N-G.; SCHWEIZER, T.F.; DeVRIES, J.W.; FURDA, I Determination of insoluble, soluble and total dietary fiber in foods and food products: Inter-laboratory study. Journal of the AOAC, v.71, p.10171023, 1988

RAINBIRD, A.L.; LOW, A.G. Effect of guar gum on gastric emptying in growing pigs. British Journal of Nutrition, v.55, p.87-98, 1986.

RAUPP, D.S.; SGARBIERI, V.C. Efeitos de frações fibrosas extraídas de feijão (Phaseolus vulgaris, L.) na utilização de macro e micronutrientes da dieta pelo rato. Ciência e Tecnologia de Alimentos, v.16, p.100-107, 1996.

RAUPP, D.S.; MOREIRA, S.S.; BANZATTO, D.A.; SGARBIERI, V.C. Composição e propriedades fisiológico-nutritivas de uma farinha rica em fibra insolúvel obtida do resíduo fibroso de fécula de mandioca. Ciência e Tecnologia de Alimentos, v.19, p.205-210, 1999.

REEVES, P.G.; NIELSEN, F.H.; FAHEY JR., G.C. AIN-93 Purified diets for laboratory rodents: Final report of the American Institute of Nutrition Ad Hoc Writing Committee on the Reformulation of the Ain- $76^{A}$ Rodent Diet. Journal of Nutrition, v.123, p.1939-1951, 1993. 
REDDY, S.; SANDERS, T.A.; OWEN, R.W.; THOMPSON, M.H. Faecal pH, bile acid and sterol concentrations in premenopausal Indian and white vegetarians compared with white omnivores. British Journal of Nutrition, v.79, p.495-500, 1998.

RIGAUD, D.; PAYCHA, F.; MEULEMANS, A.; MERROUCHE, M.; MIGNON, $M$. Effect of psyllium on gastric emptying, hunger feeling and food intake in normal volunteers: a double blind study. European Journal of Clinical Nutrition, v.52, p.239-245, 1998.

SANDBERG, A-S.; AHDERINNE, R.; ANDERSSON, H.; HALLGREN, B.; HULTEN, L. The effect of citrus pectin on the absorption of nutrients in the small intestine. Human Nutrition and Clinical Nutrition, v.37, p.171183,1983

SCHWARTZ, S.E.; LEVINE, G.D. Effect of dietary fibre on intestinal glucose absorption and glucose tolerance in rats. Journal of Gastroenterology, v.79, p.833-836, 1980.

SCHWEIZER, T.F.; EDWARDS, C.A. Dietary fibre: a component of food; nutritional function in health and disease. London: Springer-Verlag, 1992. $354 \mathrm{p}$.
SLAVIN, J.L.; MARLETT, J.A. Effect of refined cellulose on apparent energy, fat and nitrogen digestibilitiea. Journal of Nutrition, v.110, p.2000-2006, 1980

TOMA, R.B.; CURTIS, D.J. Dietary fiber: effect on mineral bioavailability. Food Technology, v.2, p.111-116, 1986.

VAHOUNY, G.V.; TOMBES, R.; CASSIDY, M.M.; KRITCHEVSKY, D.; GALLO, L.L. Dietary fibres: V. binding of bile salts, phospholipids and cholesterol from mixed micelles by bile acid sequestrants and dietary fibres. Lipids. v.15, p.1012-1018, 1980

WU, A-L.; CLARK, S.B.; HOLT, P.R. Composition of lymph chylomicrons from proximal or distal rat small intestine. American Journal of Clinical Nutrition, v.33, p.582-589, 1980.

Recebido em 18.12 .00 